\title{
Local recurrence of choroidal malignant melanoma following enucleation
}

\author{
R. F. SANKE, J. R. O. COLlin, A. GARNER, AND R. B. S. PACKARD \\ From the Institute of Ophthalmology, and Moorfields Eye Hospital, City Road, London
}

SUMMARY 542 cases of choroidal malignant melanoma were reviewed. Local recurrence occurred in only 6 patients $(1 \cdot 11 \%)$. Five of the 6 patients had distant metastases when the local recurrence was diagnosed, and the remaining patient also developed metastases after a passage of time. These figures do not support the concept of withholding a primary implant at the time of enucleation.

The chance of a malignant melanoma recurring in the orbit following an enucleation is small. The cosmetic defect from not placing an implant at the time of surgery is significant (Figs. 1 and 2). Some surgeons do not place an implant because of the theoretical risk of failure to detect a recurrence. This study was carried out to determine the incidence of local recurrence after surgery for malignant melanoma and its relationship to extrachoroidal extension and other factors.

\section{Subjects and materials}

542 cases of malignant melanoma from Moorfields

Correspondence to J. R. O. Collin, FRCS, Moorfields Eye Hospital, City Road, London EC1V 2PD.
Eye Hospital and the Cancer Registry of the Institute of Ophthalmology, London, were reviewed. All had undergone enucleation for their tumour and were followed up for a minimum of 5 years or until their death if this occurred earlier. The average duration of follow-up for those who were living or had died of unrelated causes was 11.0 years with the longest period being 26.5 years. The average survival time for those who died from their tumour was $5 \cdot 4$ years.

The histological reports were studied in addition to the clinical records. Specific attention was directed to the tumour cell type and the presence of tumour extension from the choroid into the sclera or episcleral tissues and into the neurovascular channels passing through the sclera.
Fig. 1 26-year-old patient 2 years after enucleation of left eye for a choroidal malignant melanoma. No implant was positioned at enucleation.

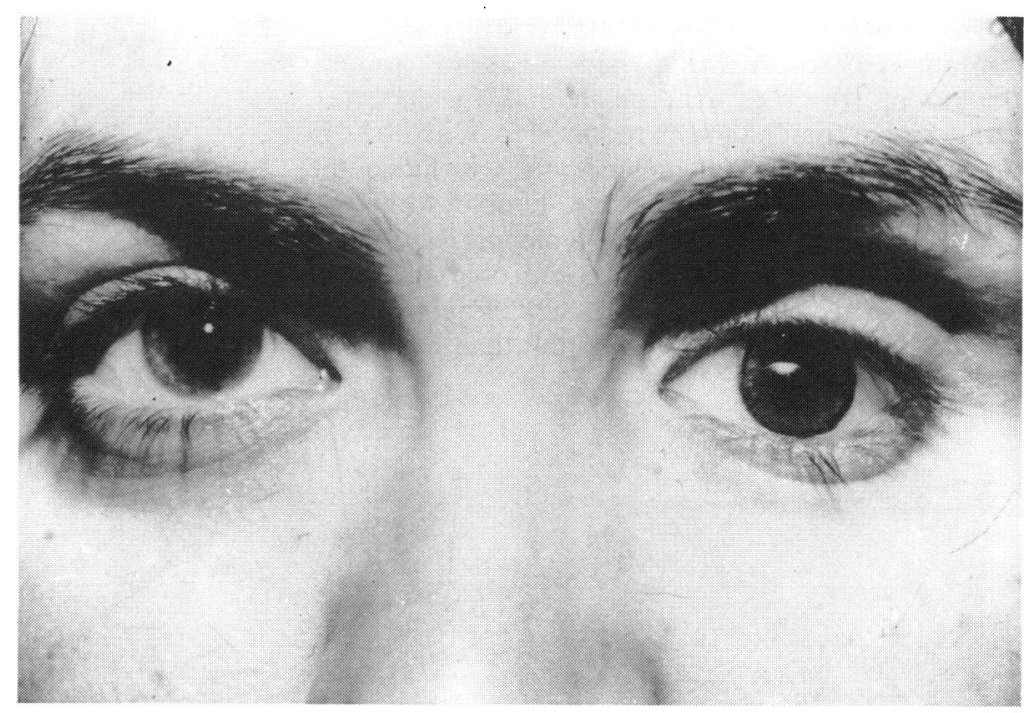




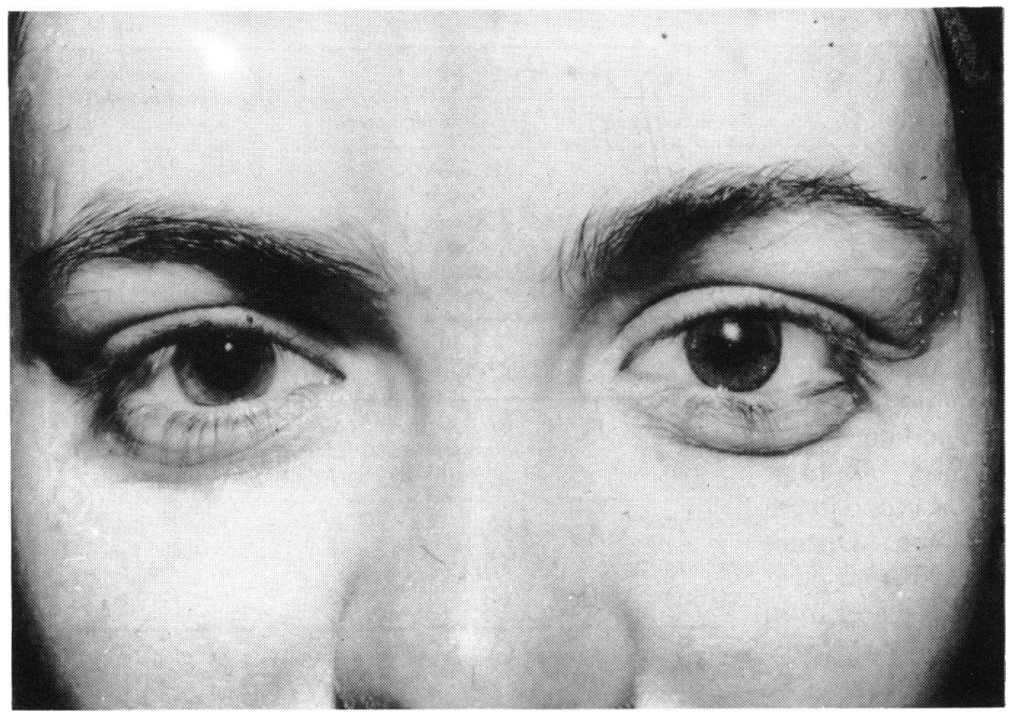

Fig. 2 Same patient after insertion of an orbital implant to correct the volume deficit.

Local recurrence of tumour occurred in only 6 cases, which are reported here.

\section{Case reports}

\section{CASE 1}

A 73-year-old woman presented with a history of 'poor vision' for 12 months and was noted to have an elevated mass in the posterior fundus of her left eye. She declined any further examination or treatment. After 20 months had passed she returned with the complaint of ocular pain and was found to have increased intraocular pressure and rubeosis in the left eye. An enucleation was performed at this time. Histological examination revealed a spindle-cell type of malignant melanoma of the choroid with 'extraocular spread and invasion of the scleral channels'. There was no local spread on gross examination at the time of surgery. Thirteen months later a local recurrence was found in the socket plus distant metastases. Because of the patient's poor general health and advanced age it was decided to treat her conservatively. She died 28 months later with multiple secondary metatases throughout her body.

\section{CASE 2}

A 56-year-old man presented at hospital with a 4month history of a painful left eye secondary to acute glaucoma. An orbital mass was noted at this time, and biopsy of the mass revealed a mixed-cell type of malignant melanoma. The tumour was in the choroid and had obvious extrascleral extensions. An exenteration of the left orbit was performed, and the orbit was lined with a skin graft taken from the leg. Examination $3 \frac{1}{2}$ months afterwards revealed a raised, bluish area on the grafted floor of the orbit, which was diagnosed as a local recurrence. Distant metastases were also diagnosed, and despite radiation treatment with cobalt he died 5 months later from generalised metastases to the major organs of the body.

\section{CASE 3}

A 51-year-old man presented to hospital with a 12month history of deteriorating vision and pain in his left eye. A diagnosis of tumour with retinal detachment was made and enucleation performed. Histopathological examination revealed a mixed-cell type of malignant melanoma of the choroid with 'extraocular extension'. No local extension was visible at the time of surgery. The patient died 30 months after enucleation from generalised metastases to the major organs of the body, including the brain. At necropsy tumour was noted in the tissues of the posterior orbit. Clinically there were no signs of local recurrence prior to the patient's death.

\section{CASE 4}

A 48-year-old woman underwent enucleation of her right eye for tumour, and the histopathological examination revealed a mixed-cell type of malignant melanoma of the choroid with 'no extraocular extension or local invasion'. Six years after enucleation a local recurrence was found in the orbit plus a distant metastasis to the skin proved by biopsy. One week later the patient died, the victim of suicide.

\section{CASE 5}

A 56-year-old man presented to hospital with a 6week history of flashing lights followed by loss of 
Table 1 Characteristics of patients showing local recurrence

\begin{tabular}{|c|c|c|c|c|c|c|}
\hline \multirow[t]{2}{*}{ Patient } & \multirow{2}{*}{$\begin{array}{l}\text { Age at time of } \\
\text { enucleation (years) }\end{array}$} & \multirow[t]{2}{*}{ Sex } & \multirow[t]{2}{*}{ Cell type } & \multicolumn{2}{|c|}{ Extrachoroidal extension } & \multirow{2}{*}{$\begin{array}{l}\text { Time from enucleation to } \\
\text { recurrence (months) }\end{array}$} \\
\hline & & & & Histological & Gross (at surgery) & \\
\hline 1 & 75 & $\mathrm{~F}$ & Spindle cell & Present & Present & 13 \\
\hline 2 & 56 & $\mathbf{M}$ & Mixed cell & Present & Present & $31 / 2$ \\
\hline 3 & 51 & $\mathbf{M}$ & Mixed cell & Present & Absent & 30 \\
\hline 4 & 48 & $\mathbf{F}$ & Mixed cell & Absent & Absent & 78 \\
\hline 5 & 56 & $\mathbf{M}$ & Spindle cell & Absent & Absent & 14 \\
\hline 6 & 44 & $\mathbf{M}$ & Mixed cell & Present & Absent & 72 \\
\hline
\end{tabular}

vision in his right eye. He underwent enucleation of that eye, and histopathological examination revealed a spindle-cell type of malignant melanoma of the choroid with 'no extraocular extension'. A firm, bluish-black subconjunctival nodule was found in the right orbital tissues 14 months later. Distant metastases to the skin and liver were also diagnosed at this same time. The patient died 3 months later from multiple secondary metastases.

CASE 6

A 44-year-old man underwent enucleation of his right eye for tumour, and histopathological examination revealed a mixed-cell type of malignant melanoma of the choroid with 'extension into the neurovascular channels but no extraocular extension'. At routine examination 6 years after enucleation a bluish-black mass was noted in the orbital tissues of that eye, and an exenteration was performed. The patient was asymptomatic until $4 \frac{1}{2}$ years after exenteration (and $10 \frac{1}{2}$ years after enucleation), when he noticed a lump in his epigastrium which was diagnosed as a metastatic lesion. He died 5 months afterwards from secondary metastases.

\section{Results}

Review of the 542 cases showed that 169 patients $(31 \cdot 18 \%)$ had metastases and died as a result of their tumour. The remaining 373 patients were alive and without recurrence, either local or systemic, for a minimum of 5 years after enucleation or else had died from causes unrelated to their tumour with no apparent tumour spread at the time of their death. A total of only 6 patients $(1 \cdot 11 \%)$ had a local recurrence in the orbit.

In all but one of the 6 cases with local recurrence this was diagnosed at the same time or after distant metastases had occurred. In the one case in which a local recurrence was diagnosed before a distant metastasis was noted the patient was treated by exenteration but died subsequently of distant metastases.

In 2 cases extraocular extension of the tumour was visible at the time of surgery. In 2 cases extraocular extension was not suspected at the time of surgery,
Table 2 Cell type and clinical behaviour

\begin{tabular}{llll}
\hline & $\begin{array}{l}\text { No } \\
\text { metastasis } \\
\text { (359 cases) }\end{array}$ & $\begin{array}{l}\text { Metastasis } \\
\text { present } \\
(169 \text { cases })\end{array}$ & $\begin{array}{l}\text { Per cent of } \\
\text { cell tvpe with } \\
\text { metastasis }\end{array}$ \\
\hline $\begin{array}{l}\text { Spindle cell* } \\
\text { Mixed cell }\end{array}$ & 270 & 79 & $22 \cdot 64 \%$ \\
$\begin{array}{l}\text { Epithelial cell } \\
\text { Necrotic }\end{array}$ & 61 & 63 & $50 \cdot 81 \%$ \\
\hline
\end{tabular}

*Includes both spindle cell A and B types.

but the histology reports showed microscopical extrascleral extension of the tumour. In the remaining 2 cases there was no evidence of extraocular spread either at surgery or on subsequent histological examination of the enucleated eye. Four of the cases had mixed-cell tumours and 2 had spindle-cell tumours. These findings are summarised in Table 1.

Examination of the histopathological reports of the whole series showed 528 cases that were sufficiently clear and complete to allow correlation of cell type and presence of microscopic extension with the clinical behaviour of the tumour. Table 2 shows the relationship of cell type to metastases. The highest incidence of metastases occurred with epithelial-cell or mixed-cell tumours. The relationship between scleral and neurovascular extension and the clinical behaviour of the tumour is presented in Table 3 . Of the 51 cases that had extension into the episcleral tissues on histology, 21 cases $(41 \cdot 18 \%)$ had no evidence of local recurrence or metastases after a minimum follow-up of 5 years.

\section{Discussion}

A noticeable finding in this study is the rarity of local recurrence of choroidal malignant melanomas

Table 3 Tumour extension and clinical behaviour

\begin{tabular}{lccl}
\hline & $\begin{array}{l}\text { No } \\
\text { metastasis }\end{array}$ & $\begin{array}{l}\text { Metastasis } \\
\text { present } \\
(169 \text { cases })\end{array}$ & $\begin{array}{l}\text { Per cent } \\
\text { developing } \\
\text { metastasis }\end{array}$ \\
\hline No extrachoroidal extension & 199 & 39 & $16 \cdot 39 \%$ \\
Neurovascular scleral extension & 165 & 146 & $46 \cdot 95 \%$ \\
Episcleral extension & 21 & 30 & $58 \cdot 82 \%$ \\
\hline
\end{tabular}


following enucleation. It was found that almost onethird of cases eventually developed metastases, yet only $1 \%$ of cases developed a local recurrence in the orbital tissues themselves. The study of Starr and Zimmerman, which included both ciliary body and choroidal melanomas, showed a 3\% local recurrence rate, which is similar to but slightly higher than our findings. ${ }^{1}$

Since the incidence of local recurrence is so low, and since when a local recurrence does occur distant metastases are usually already present, we think that an orbital implant should be placed at the time of enucleation provided there is no visible extraocular extension. If an implant is not positioned at enucleation, the cosmetic defect from the resulting volume deficit can be considerable (Fig. 1). If an attempt is made to correct this volume deficit with a large prosthesis, the lower lid stretches with the weight of the prosthesis, and the enophthalmic appearance recurs with a deep upper lid sulcus and ptosis. ${ }^{2}$ The only way to correct this is with a buried implant, and this requires an additional operation, which could be avoided if the implant was positioned at the time of the original enucleation (Fig. 2). Cosmesis is particularly important for the younger patient whose social and work situations are more sensitive than those of the older patient. An avoidable cosmetic defect is a serious disadvantage to such a patient and is not justifiable unless the life expectancy is increased by not correcting the defect. Our findings do not show this.

Local recurrence is influenced by the cell type. The overall incidence of the mixed-cell type of melanoma was $23 \%$ whereas it occurred in 4 of the 6 cases with local recurrence. This cell type is generally considered to be more aggressive than the spindle-cell types, ${ }^{13}$ and our findings support this. Those other factors in addition to the cell type which affect the prognosis for malignant melanoma in general, such as increasing age in the patient and extraocular spread at the time of enucleation, ${ }^{45}$ also influence the chance of local recurrence. In our series the incidence of local recurrence was higher if there was extrascleral spread at the time of surgery, but in $41 \%$ of cases which showed histological evidence of extrascleral extension there was no local recurrence or metastases after a minimum follow-up period of 5 years. This is similar to the findings of Starr and Zimmerman. ${ }^{1}$ Chisholm in his long-term follow-up of melanoma patients reported several with tumour extension into and beyond the sclera who had survived without local recurrence or metastases for more than 25 years after enucleation. ${ }^{6}$ Duke-Elder on the other hand cited cases of local recurrence which occurred after periods ranging from 12 to 30 years following enucleation. ${ }^{7}$ Since a local recurrence can occur after such prolonged periods of time, there is no justification for recommending that a patient should wait to have an orbital implant inserted as a secondary procedure.

\section{References}

1 Starr HJ, Zimmerman LE. Extrascleral extension and orbital recurrence of malignant melanomas of the choroid and ciliary body. Int Ophthalmol Clin 1962; 2: 369-85.

2 Bartlett RE. Plastic surgery for the enucleation patient. Am J Ophthalmol 1966; 61: 68-78.

3 Shammas HF, Blodi FC. Orbital extension of choroidal and ciliary body melanomas. Arch Ophthalmol 1977; 95: 2002-5.

4 Benjamin B. Cumings JH, Goldsmith AJB. Sorsby A. Prognosis in uveal melanoma. Br J Ophthalmol 1948; 32: 729-38.

5 Shammas HF, Blodi FC. Prognostic factors in choroidal and ciliary body melanomas. Arch Ophthalmol 1977; 95: 63-9.

6 Chisholm JF. A long term follow-up on malignant melanomas of the choroid based on the Terry and Jones series. Am J Ophthalmol 1953; 36: 61-73.

7 Duke-Elder S. Diseases of the uveal tract. System of Ophthalmology. London: Kimpton, 1966; 9: 910. 